\title{
In-Process Prediction of Straightness in CNC Turning by Using Wavelet Transform
}

\author{
Mumin Sassantiwong and Somkiat Tangjitsitcharoen* \\ Department of Industrial Engineering, Faculty of Engineering, Chulalongkorn University, Phayathai Road, Patumwan, Bangkok, \\ 10330, Thailand \\ *Corresponding author
}

\begin{abstract}
The aim of this research is to monitor the dynamic cutting forces in CNC turning process in order to investigate the relation between the straightness and the dynamic cutting forces. The dynamic cutting forces occurred during the CNC turning process include the straightness and noise signals. The Daubechies wavelet transform is applied to identify those signals into different levels due to the different frequencies. The experimentally obtained results showed that the dynamic cutting forces can be used to predict the straightness under various cutting conditions in the further research by utilizing the wavelet transform.
\end{abstract}

Keywords-turning; dynamic cutting forces; straightness; wavelet transform

\section{INTRODUCTION}

Recently, the in-process prediction of straightness and roundness in CNC turning process has been proposed by using the cutting force ratio [1-2]. However, the cutting forces cannot be used well to predict the straightness and roundness when the noise signals appear. The relation between the surface roughness and the cutting force had been investigated by using the different cutting tools and the cutting parameters [3].

The cutting force signals have been monitored to examine the cutting performance in the turning process [4-6]. It is proved that the in-process surface roughness can be predicted well in CNC turning process by using the ratio of dynamic cutting forces [7]. The force sensor is employed to detect the chatter in the grinding process [8] and the milling process [9]. The cutting force ratio can help to cut off the effects of cutting conditions and reduce the data-processing time from the use of Fast Fourier Transform (FFT) technique. The Fast Fourier Transform (FFT) is generally adopted to analyze the chatter signals in frequency domain but it cannot be used to identify the surface roughness signals from the dynamic cutting forces in time domain [10]. However, the dynamic cutting forces in time domain may include the straightness signal which is mixed with other signals such as the broken chip signals in both time and frequency domains.

The wavelet transform is proposed to decompose the dynamic cutting forces into many levels to analyze the chatter signal both time and frequency domains [11-13]. It is found that the decomposed cutting forces by using the Daubechies wavelet transform can be used to detect the chatter frequency effectively at the lower level of the decomposed cutting forces.
It is implied if the noise signals can be detected and separated out from the straightness signal into other levels of the wavelet transform, the straightness will be effectively identified on the decomposed cutting forces. Hence, the aim of this research is to propose the Daubechies wavelet transform to decompose the dynamic cutting forces in order to analyze the straightness signal in CNC turning process. The straightness frequency is expected to be happened at the higher level of the decomposed cutting forces but the noise signals will appear at the lower levels due to the higher frequency of itself.

\section{MONITORING OF DYNAMIC CUTTING FORCES}

The preliminary experiments have been conducted with the carbon steel S45C and the coated carbide tools to monitor the dynamic cutting forces as shown in Figures 1 and 2. The cutting forces which are radial force $\left(F_{x}\right)$, the feed force $\left(F_{y}\right)$ and the main force $\left(\mathrm{F}_{\mathrm{z}}\right)$ will be detected and obtained by the dynamometer installed on the turret of CNC turning machine. The cutting speed is $200 \mathrm{~m} / \mathrm{min}$ while the feed rate, the depth of cut, the tool nose radius and the rake angle are $0.2 \mathrm{~mm} / \mathrm{rev}$, $0.6 \mathrm{~mm}, 0.8 \mathrm{~mm}$ and $-6^{\circ}$, respectively.

The straightness can be measured off-line firstly by using the straightness tester. Figure 1 illustrates the dynamic cutting forces and the corresponding time records of the straightness in the time domain. Figure 2 shows their power spectrum density (PSD) in the frequency domain by taking the FFT. It is understood that the frequency of the straightness is correspondent with the frequency of the dynamic cutting forces in frequency domain which is $34 \mathrm{~Hz}$.

Figures 3 and 4 showed the dynamic cutting forces and the straightness signals obtained from the cutting speed of 100 $\mathrm{m} / \mathrm{min}$, the feed rate of $0.25 \mathrm{~mm} / \mathrm{rev}$, the depth of cut of 0.8 $\mathrm{mm}$, the tool nose radius of $0.8 \mathrm{~mm}$ and the rake angle of $-6^{\circ}$. The broken chips occurred at this cutting conditions mixed with the long curl chips. The long curl chip can be observed on Figure 4 at the lower frequency range which is lower than the straightness frequency of $19 \mathrm{~Hz}$. It can be seen that the straightness signal is difficult to classify from the dynamic cutting forces in both time and frequency domains by using FFT when the broken chips and the noise signals appear. Hence, the Daubechies wavelet transform is required to separate the straightness signal and the noise signals which are mixed on the dynamic cutting forces. 


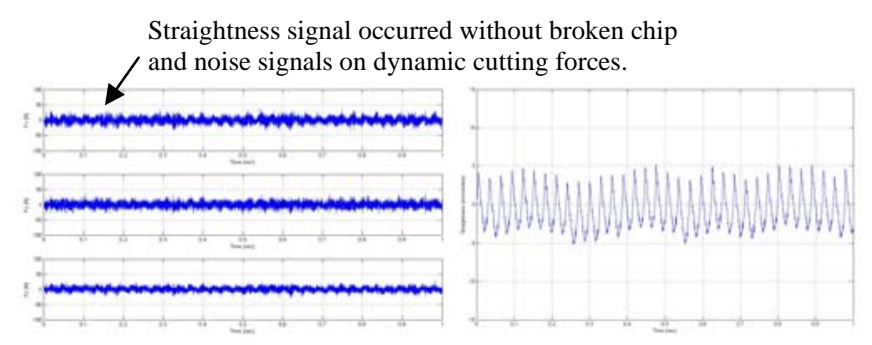

FIGURE I. EXAMPLE OF DYNAMIC CUTTING FORCES AND STRAIGHTNESS SIGNAL IN TIME DOMAIN.
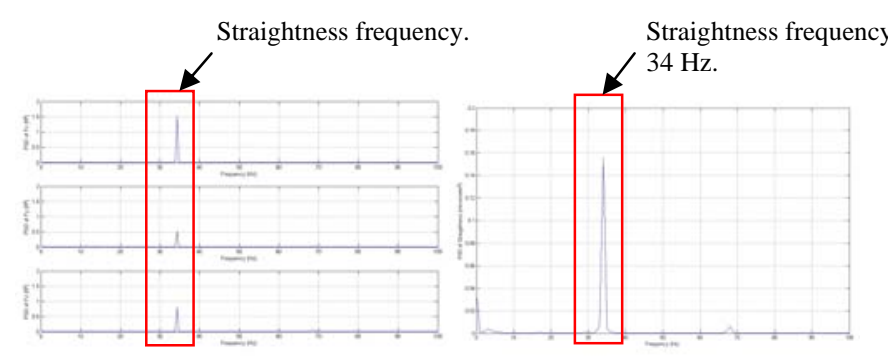

FIGURE II. EXAMPLE OF PSD OF DYNAMIC CUTTING FORCES AND STRAIGHTNESS IN FREQUENCY DOMAIN.

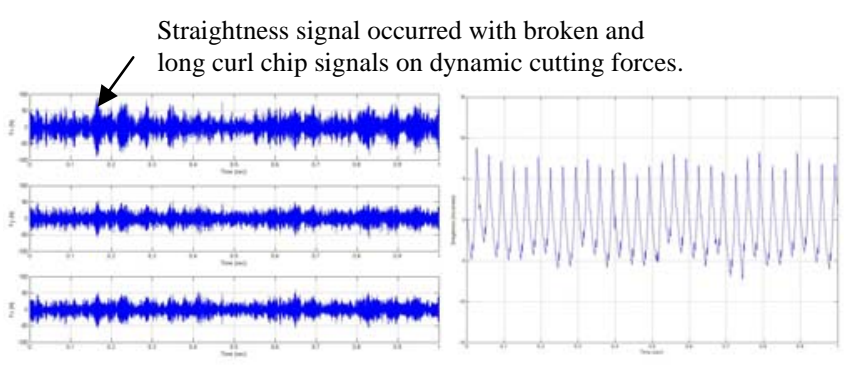

FIGURE III. EXAMPLE OF DYNAMIC CUTTING FORCES AND STRAIGHTNESS SIGNAL IN TIME DOMAIN.

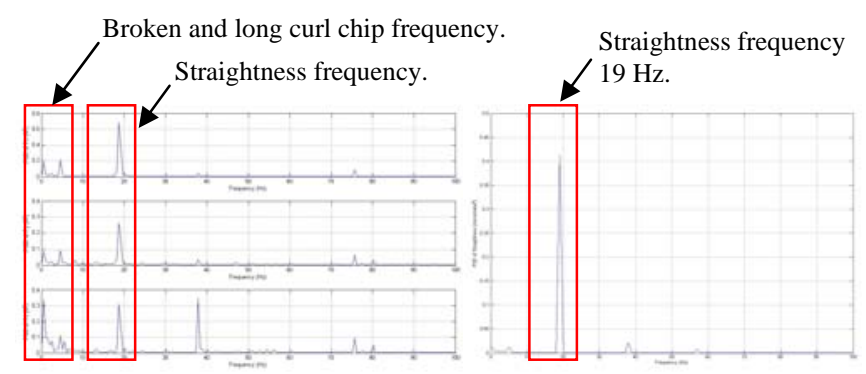

FIGURE IV. EXAMPLE OF PSD OF DYNAMIC CUTTING FORCES AND STRAIGHTNESS IN FREQUENCY DOMAIN.

\section{EXPERIMENTAL SETUP AND PROCEDURE}

The series of experiments are performed by using the coated carbide cutting tools with the carbon steel (S45C). The dynamometer (Kistler 9121) is installed to monitor the dynamic cutting forces on the turret of CNC turning machine as shown in Figure 5. The straightness tester of Mitsutoyo SJ-400 is employed to measure the straightness of the machined workpiece.

The cutting conditions are listed in Table 1. The dynamic cutting forces are sampling and low-pass filtered with the cutoff frequency of $10 \mathrm{kHz}$ and $5 \mathrm{kHz}$, respectively. The dynamic cutting forces will be decomposed into 10 levels of the Daubechies wavelet transform to monitor and classify the straightness signal and the noise signals.

TABLE I. CUTTING CONDITIONS.

\begin{tabular}{|l|c|}
\hline Cutting speed $(\mathrm{m} / \mathrm{min})$ & $100,150,200$ \\
\hline Feed rate $(\mathrm{mm} / \mathrm{rev})$ & $0.2,0.25$ \\
\hline Depth of cut $(\mathrm{mm})$ & $0.6,0.8$ \\
\hline Tool nose radius & $0.4,0.8$ \\
\hline Rake angle & -6 \\
\hline
\end{tabular}

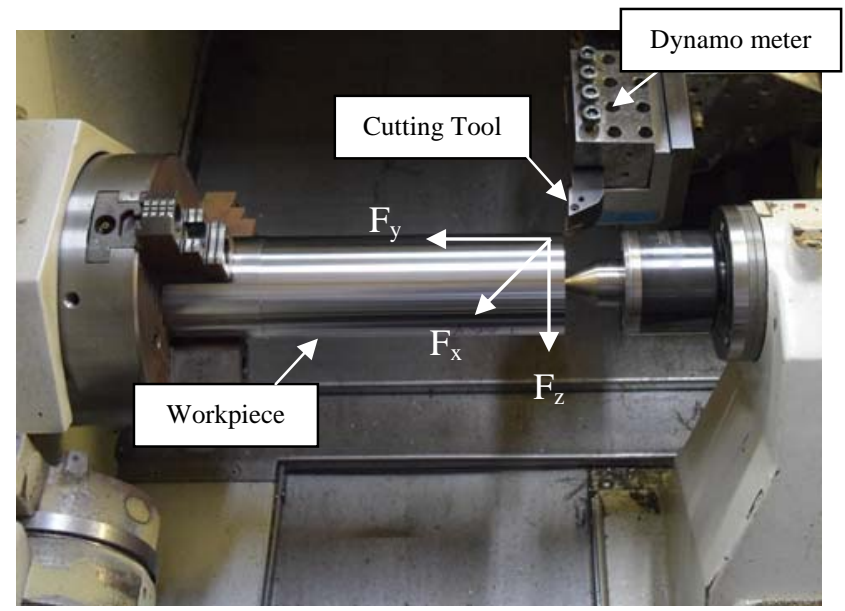

FIGURE V. ILLUSTRATION OF EXPERIMENTAL SETUP.

\section{EXPERIMENTAL RESULTS AND DISCUSSION}

The examples of the cutting tests are illustrated in Figures 6 and 7. The dynamic cutting forces are decomposed into 10 levels in the time domain and the frequency domain by using the Daubechies wavelet transform as shown in Figure 6 and Figure 7 , respectively. It is shown that the frequency of the decomposed cutting force corresponds with the straightness frequency at the 8th level. Hence, the decomposed cutting force from the 8th level can be monitored to estimate the in-process straightness.

Since the broken chip and noise signals have been classified out from the straightness signal as shown in Figures 6 and 7. It is understood that the higher frequency signals over than 100 $\mathrm{Hz}$ to $1000 \mathrm{~Hz}$, which are the broken chip and noise signals, will appear at the lower levels of the wavelet transform.

On the other hand, the lower frequency signal of the straightness frequency of $26 \mathrm{~Hz}$ will happen at the higher level of the wavelet transform, which is the 8th level as shown in Figure 8. 

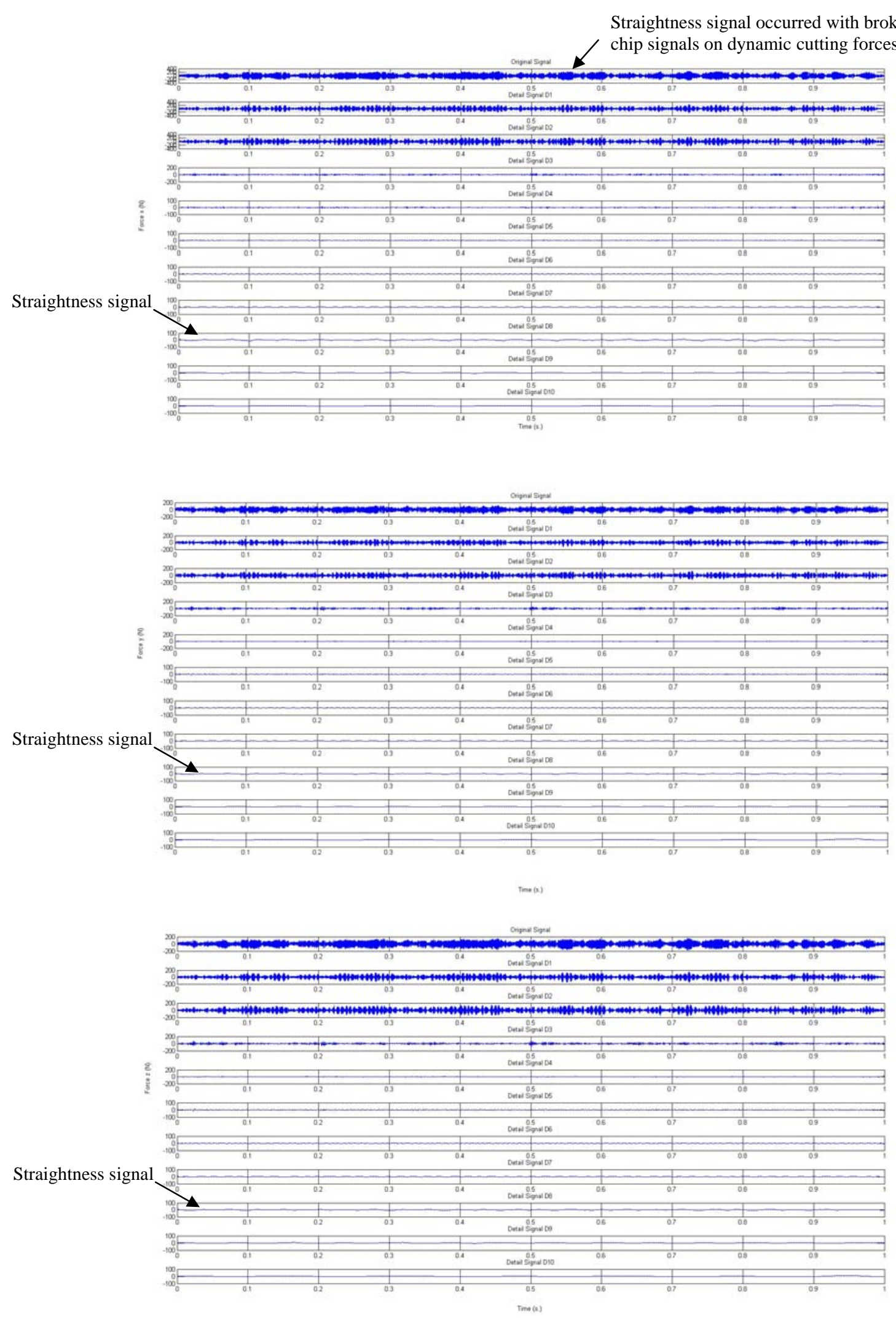

FIGURE VI. EXAMPLE OF DECOMPOSED CUTTING FORCES IN TIME DOMAIN USING CUTTING SPEED OF 150 M/MIN, FEED RATE OF 0.25 MM/REV, DEPTH OF CUT OF 0.6 MM, TOOL NOSE RADIUS OF 0.4 AND RAKE ANGLE OF $-6^{\circ}$. 

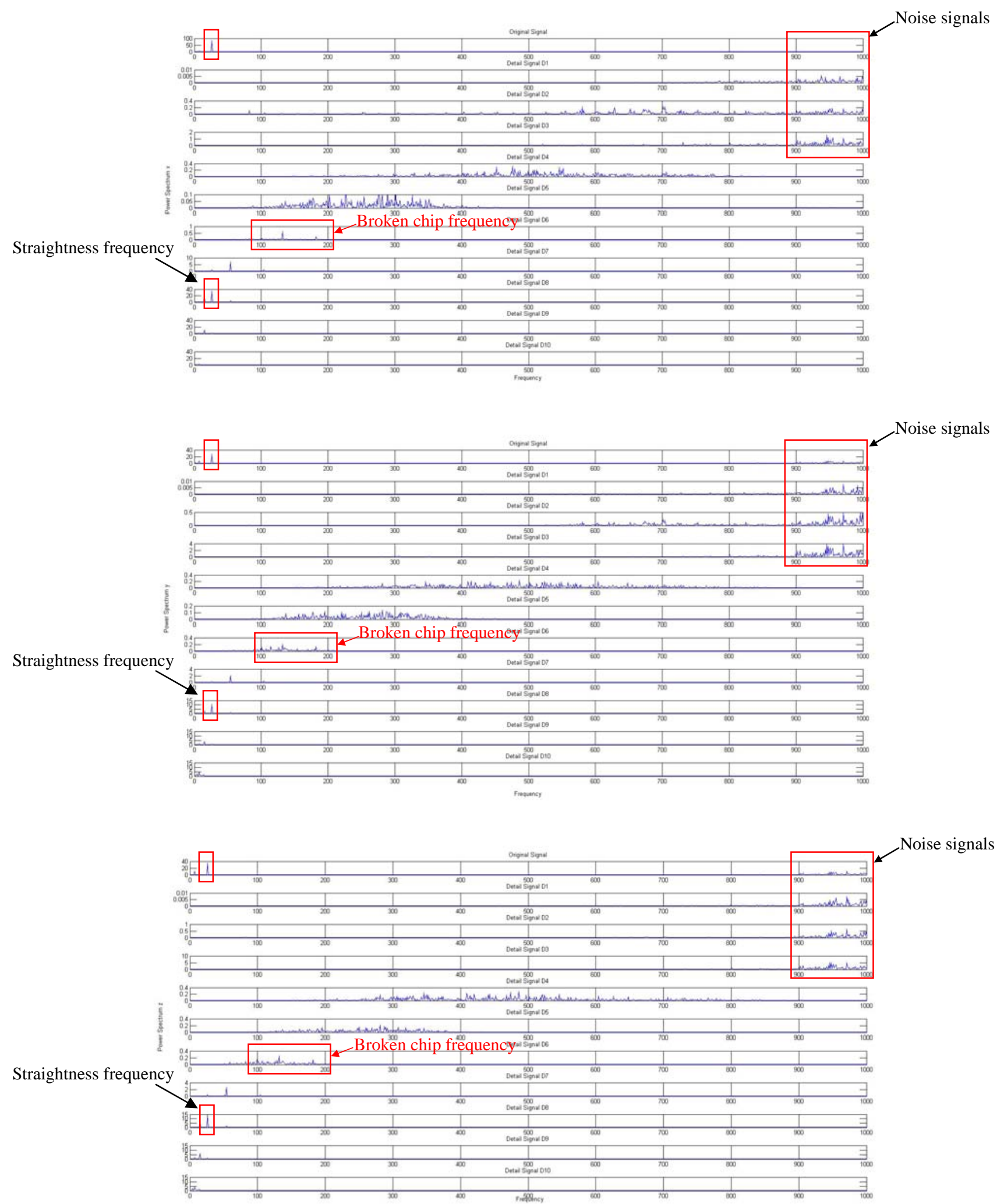

FIGURE VII. EXAMPLE OF DECOMPOSED CUTTING FORCES IN FREQUENCY DOMAIN USING CUTTING SPEED OF 150 M/MIN, FEED RATE OF $0.25 \mathrm{MM} / \mathrm{REV}$, DEPTH OF CUT OF 0.6 MM, TOOL NOSE RADIUS OF 0.4 AND RAKE ANGLE OF $-6^{\circ}$. 

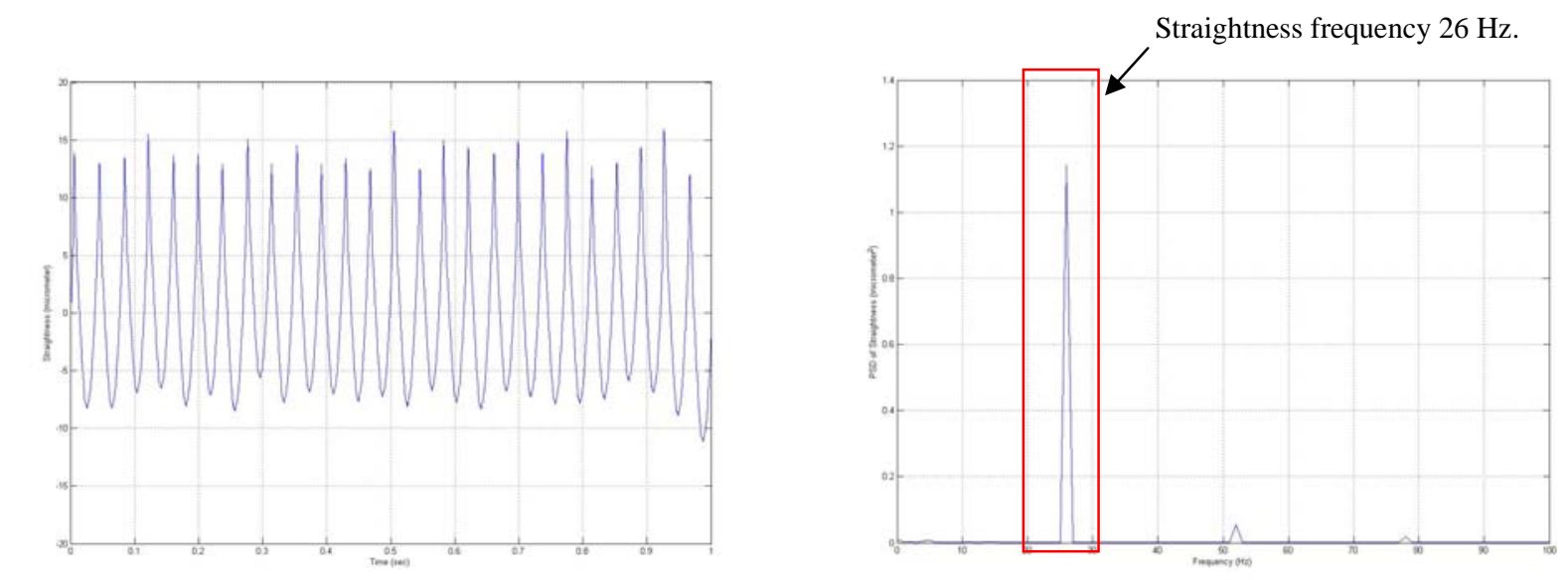

FIGURE VIII. ILLUSTRATION OF STRAIGHTNESS IN TIME DOMAIN AND ITS PSD IN FREQUENCY DOMAIN USING CUTTING SPEED OF 150 M/MIN, FEED RATE OF 0.25 MM/REV, DEPTH OF CUT OF 0.6 MM, TOOL NOSE RADIUS OF 0.4 AND RAKE ANGLE OF - $6^{\circ}$.

\section{CONCLUSION}

The dynamic cutting forces in CNC turning process are monitored to analyze the straightness signal. However, the straightness signal cannot be classified from the dynamic cutting forces and separated out from the broken chip and noise signals in both time and frequency domains by using the FFT technique. The Daubechies wavelet transform is proposed to decompose the dynamic cutting forces into 10 levels in both time and frequency domains to determine the suitable level of the straightness signal, which is the 8th level. It is understood that the decomposed cutting forces obtained from the 8th level can be considered to predict the straightness in the future research.

\section{ACKNOWLEDGMENT}

This work was performed by the partial funding of The Thailand Research Fund (TRF).

\section{REFERENCES}

[1] T. Shansungnoen and S. Tangjitsitcharoen, "Investigation of relation between Straightness and Cutting Force in CNC Turning Process," Appl Mech Mater. vol. 789-790, pp. 812-820, 2015.

[2] D. Chanthana and S. Tangjitsitcharoen, "A Study of Relation between Roundness and Cutting Force in CNC Turning Process," Appl Mech Mater. vol. 799-800, pp. 366-371, 2015.

[3] S. Tangjitsitcharoen, K. Samanmit, and S. Ratanakuakangwan, "Development of surface roughness prediction by utilizing dynamic cutting force ratio,” Appl Mech Mater. vol. 490-491, pp. 207-212, 2014.

[4] Z. Hessainia, A. Belbah, M.A. Yallese, T. Mabrouki, and J.F. Rigal, "On the prediction of surface roughness in the hard turning based on cutting parameters and tool vibrations," Measurement vol. 46, pp. 1671-1681, June 2013.

[5] P. Venkataramaiah, K. DharmaReddy, and P. Meramma, "Analysis on influence of feed rate and tool geometry on cutting forces in turning using Taguchi method and Fuzzy logic," Procedia Mater. Sci. vol. 5, pp. 1692-1701, 2014.

[6] S. Yaldiz and F. Unsacar, "Design, development and testing of a turning dynamometer for cutting force measurement," Mater Design, vol. 27, pp. 839-846, 2006.
[7] S. Tangjitsitcharoen, "Advanced Prediction of surface roughness by monitoring of dynamic cutting forces in CNC turning process," Appl Mech Mater, vol. 239-240, pp. 661-669, 2013.

[8] S. Tangjitsitcharoen and A. Senjuntichai, "In-Process Chatter Detection in Surface Grinding,” MATEC Web of Conferences, vol. 28, pp. 02001p.1-02001-p.9, 2015.

[9] S. Tangjitsitcharoen and N. Pongsathonwiwat, "Development of chatter detection in milling processes," Int J Adv Manuf Tech, vol. 65, pp. 919927, 2013.

[10] E. Kuljanic, G. Totis, and M. Sortino, "Development of an intelligent multi sensor chatter detection system in milling," Mech Syst Sig Process, vol. 23(5), pp. 1704-1718, 2009.

[11] S. Tangjitsitcharoen, S. Tanintorn, and S. Ratanakuakangwan, "Advance in chatter detection in ball end milling process by utilizing wavelet transform,” J Intell Manuf. DOI: 10.1007/s10845-013-0805-3, 2013.

[12] Addison PS. The illustrated wavelet transform handbook, introductory theory and applications in science, engineering, medicine and finance 2002. Institute of Physics Publishing Bristol and Philadelphia.

[13] A. Graps, "An introduction to wavelets," Comput Sci Eng, IEEE, 1995, vol. 2(2), pp. 50-61. 